\title{
The Development Trend of Logistics Supply Chain Management in Taiwan
}

\author{
Dingtao Zhao ${ }^{1}$, Su-Hui Kuo ${ }^{1}$, Tien-Chin Wang ${ }^{2, *}$ \\ ${ }^{1}$ Dept. of Business Administration, University of Science and Technology of China, Hefei, China \\ ${ }^{2}$ Dept. of International Business, National Kaohsiung University of Applied Sciences, Kaohsiung, Taiwan
}

\section{Email address:}

box@ustc.edu.cn (Dingtao Zhao), kcsophia@yahoo.com.tw (Su-Hui Kuo), tcwang@kuas.edu.tw (Tien-Chin Wang)

${ }^{*}$ Corresponding author

\section{To cite this article:}

Dingtao Zhao, Su-Hui Kuo, Tien-Chin Wang. The Development Trend of Logistics Supply Chain Management in Taiwan. Science Innovation. Vol. 4, No. 6, 2016, pp. 311-316. doi: 10.11648/j.si.20160406.21

Received: November 17, 2016; Accepted: December 7, 2016; Published: January 4, 2017

\begin{abstract}
Logistics has become increasingly important in global deployment of enterprises over the years. International logistics, global logistics management, composite transports, and supply chain management triggered macroeconomic development and the emergence of innovative industries. In responding to the challenge of globalization, the strengthening of the cooperation among the logistics operators, suppliers, information service providers, and the customers so as to upgrade the overall logistic management efficiency including supply chain planning, procurement, manufacturing and production, and logistics support, and repair and maintenance service will be essential. This helps to hold down the cost of supply chain operation and is critical for the success of logistics operators in the competition. Logistics operators are the aggregate of supply chains from different countries. Logistics operators are bound to face a diversity of challenging issues of profound influence which dictate for the reinforcement of supply chain management thereby translating the weakness under the unpredictable operation environment into competitive advantage. This study is an attempt to explore how logistics operators can enhance their competitive advantage and upgrade the competitive power of logistic service worldwide through the deployment and integration of logistics planning, value adding and innovation of services, and information system integration for the supply chain. Through the buildup of the core competence of international logistics and the proactive integration of business flow, capital flow, and information flow, an international operation platform in superior quality can be established for creating opportunities of trade and global logistics operation for Taiwan.
\end{abstract}

Keywords: International Logistics, Supply Chain Management, Value Adding and Innovation, Information System Integration

\section{台灣物流供應鍕管理發展趨勢}

趙定濤 ${ }^{1}$, 郭淑惠 ${ }^{1}$ ，王天津 ${ }^{2 *}$

${ }^{1}$ 工商管理系, 中国科学技术大学, 合肥市, 中國

回際企業系, 高雄應用科技大學, 高雄市, 台灣

邮箱

box@ustc. edu. cn（趙定濤），kcsophia@yahoo.com.tw（郭淑惠），tcwang@kuas. edu. tw（王天津）

摘要：近年來物流對企業全球布局日漸重要, 國際物流、全球運籌、複合運輸、供應鏈管理等相關物流活動將帶動整 體經濟的發展與創新產業的興起。為因應全球化的競爭挑戰, 如何加強物流業者與供應商、資訊服務廠商以及客戶之 間的協同合作，提升從供應鏈規劃、採購、製造生產、物流配送到商品回收維修之整體供應鏈管理效率，進而降低供 應鏈成本，已成為物流業者競爭致勝的關鍵。物流業者本身及來自不同國家的供應鏈，同樣面臨多樣化且影響深遠的 
挑戰性問題, 有待物流業者加強供應鏈的管理, 將多變環境的脆弱性轉化為企業的競爭優勢。本研究旨在了解物流業 者在國際競爭趨勢下，以物流佈建與整合、服務加值與創新、資訊系統整合供應鏈，使企業提升競爭優勢，併同提升 物流服務業之國際競爭實力。透過國際物流的核心實力建構, 積極結合商流、金流、資訊流的環境, 創造優質的國際 營運平台，以支援貿易活動、創造台灣經貿運籌全球的機會。

关键词：國際物流，供應鏈管理，加值與創新，資訊系統整合

\section{1. 引言}

在全球化與委外的趨勢下，國際物流業逐漸轉型為 供應鏈管理服務業，台灣政府也開始推動「國際物流供 應鏈管理服務發展計畫」, 以促使業者轉型。物流業者 為了因應簡化供應鏈管理複雜度的挑戰, 以落實供應鏈 管理效率的提升, 正逐漸傾向將供應鏈作業委外給能夠 提供整合型物流服務的業者, 同時減少委外的物流業家 數。為因應全球化的發展與競爭, 國外國際物流業者已 經紛紛轉型為供應鏈管理服務業者, 台灣國際物流業者 也勢必朝向此方向發展, 而政府單位從今年開始推動「國 際物流供應鏈管理服務發展計畫」，以因應這樣的發展 趨勢。

這樣的趨勢是因為整個產業變動的影響所致, 企業面 臨最大的挑戰就是全球化的競爭, 所以企業開始走向全球 布局, 也因此衍生供應鏈布局的需求。企業欲專注於核心 競爭力的提升, 如研發、製造和行銷等，因此開始將非核 心業務如物流等作業委外, 但隨著供應鏈管理的作業日趨 複雜, 企業為了降低成本, 不僅將供應鏈管理作業流程中 的配銷物流（Deliver）作業委外，也逐漸將整體供應鏈 管理作業流程委外, 包含從規畫、採購、製造一直到貨品 退回所衍生的作業等。為了因應企業供應鏈委外的需求, 物流業者也勢必轉型為供應鏈管理服務業者, 以提升競爭 力。

\section{2. 物流管理 (Logistics Management) 的定義、 特點與原則}

\section{1. 物流管理的定義}

物流管理（Logistics Management）是指在社會再 生產過程中, 根據物質資料實體流動的規律, 應用管理 的基本原理和科學方法, 對物流活動進行計劃、組織、 指揮、協調、控制和監督, 使各項物流活動實現最佳的 協調與配合, 以降低物流成本, 提高物流效率和經濟效 益。現代物流管理是建立在系統論、資訊理論和控制論 的基礎上的。

\section{2. 物流管理的特點與原則}

物流管理的特點：以實現客戶滿意為第一目標; 以企 業整體最優為目的; 以信息為中心; 重效率更重效果。物流 管理的原則: 在總體上, 堅持物流合理化的原則, 就是在 兼顧成本與服務的前提下, 對物流系統的構成要素進行調 整改進, 實現物流系統整體優化。在宏觀上除了完善支撑
要素建設外, 還需要政府以及有關專業組織的規劃和指導。 在微觀上, 除了實現供應鏈的整體最優管理目標外, 還要 實現服務的專業化和增值化。現代物流管理的永恆主題是 成本和服務, 即在努力削減物流成本的基礎上, 努力提升 物流增值性服務。在服務上, 具體表現為7R原則, 即適合 的質量(Right Quality)、適合的數量(Right Quantity)、 適合的時間（Right Time）、適合的地點（Right Place）、 優良的印象（Right Impression）、適當的價格（Right Price）和適合的商品（Right Commodity）。即為客戶提 供上述 7 個方面的恰當服務。

\section{3. 物流管理的基本內容}

（1）物流作業管理：物流作業管理是指對物流活動或功 能要素的管理, 主要包括運輸與配送管理、倉儲與 物料管理、包裝管理、裝卸搬運管理、流通加工管 理、物流信息管理等等。

（2）物流戰略管理: 物流戰略管理是對企業的物流活動 實行的總體性管理, 是企業制定、實施、控制和評 價物流戰略的的一系列管理決策與行動, 其核心問 題是使企業的物流活動與環境相適應, 以實現物流 的長期、可持續發展。

（3）物流成本管理: 物流成本管理是指有關物流成本方 面的一切管理工作的總稱, 即對物流成本所進行的 計劃、組織、指揮、監督和調控。物流成本管理的 主要內容包括物流成本核算、物流成本預測、物流 成本計劃、物流成本決策、物流成本分析、物流成 本控制等。

（4）物流服務管理: 所謂物流服務, 是指物流企業或企業 的物流部門從處理客戶訂貨開始, 直至商品送交客戶 過程中, 為滿足客戶的要求, 有效地完成商品供應、 減輕客戶的物流作業負荷, 所進行的全部活動。

（5）物流組織與人力資源管理：物流組織是指專門從事 物流經營和管理活動的組織機構, 既包括企業內部 的物流管理和運作部門、企業間的物流聯盟組織, 也包括從事物流及其中介服務的部門、企業以及政 府物流管理機構。

（6）供應鏈管理：供應鏈管理是用系統的觀點通過對供 應鏈中的物流、信息流和資金流進行設計、規劃、 控制與優化, 以尋求建立供、產、銷企業以及客戶 間的戰略合作伙伴關係, 最大程度地減少內耗與浪 費, 實現供應鏈整體效率的最優化並保證供應鏈成 員取得相應的績效和利益, 來滿足顧客需求的整個 管理過程。 


\section{3. 供應鏈管理 (Supp1y Chain Management)}

\section{1 . 供應鏈管理的定義}

根據研究機構IDC的定義, 乃是指「企業將供應商與 交易夥伴整合（Integrate）至本身的組織之中，藉以最 佳化 (Optimize) 資源的分配, 及合理簡化 (Streamline) 由產品設計或概念發想至實際銷售或遞送過程中之資訊、 商品、服務的一段連續性過程」。

\section{2. 供應鏈管理系統 (SCM)}

SCM (Supply Chain Management) 供應鏈管理系統，是 從ERP基礎上發展出來的, 將企業生產製造過程、庫存管 理至供應商等方面的資料予以整合, 從而藉由單一的管控 視野, 協助企業得統一檢視所有與製造過程相關的各項影 響因素，並據此建構一個整合性的供應鏈資訊及規劃決策 機制, 且透過自動化、最佳化的資訊基礎架構軟體, 來滿 足供應鏈最佳化之目標，讓企業能在既有資源基礎上，充 分滿足客戶需求。從而藉由單一的管控視野, 協助企業得 統一檢視所有與製造過程相關的各項影響因素, 並據此建 構一個整合性的供應鏈資訊及規劃決策機制, 且透過自動 化、最佳化的資訊基礎架構軟體, 來滿足供應鏈最佳化之 目標, 讓企業能在既有資源基礎上, 充分滿足客戶需求。 SCM透過ERP連線交易處理 (OLTP) 等核心系統之上, 再經過 轉換接口, 佐以諸如ODBC等轉換技術, 整合企業各項應用 系統、以及各種資料型態。將企業內部資源、物流等項目 施以有效管理, 從原物料、成品, 一路延伸到市場客戶端; 以往企業不易善盡供應鏈管理事務的主因, 係源自於伴隨 良率等因素而來的「製造不確定性」、伴隨原物料品質或 供貨時程而來的「供應不確定性」, 以及伴隨需求預測誤 差、客戶偏好改變等因素而來的「市場不確定性」, 而SCM 的主要任務, 便是盡力掃除這3大不確定因子, 繼而幫助 企業透過有效的管理需求預測、訂單達交等正向循環, 接 著以最佳效率，把原物料製造成為市場確實有所需求的成 品, 然後在客戶所指定的時間範圍內, 將成品運抵客戶所 指定的任何地點。

\section{3. 供應鏈管理之目的}

供應鏈管理專注於管理它的資源達到下列目的:

（1）滿足客戶的需求: 提升客戶的最大滿意度，提高交 貨的可靠性和靈活性。

（2）提高競爭優勢: 降低庫存, 減少生產及分銷的費用, 降低公司的成本，提高升公司競爭優勢。

（3）達到企業營運的目標：企業整體「流程品質」最優 化, 去除錯誤成本、消弭異常事件，使企業達成營 運獲利目標。

\section{4. 供應鏈概念和技術}

（1）精實物流 (Lean Logistics)：精實物流來源於精實 生產, 精實生產作為生產領域管理技術研究的成果。 精實物流所強調的是同步操作環境, 循環時間壓縮, 全過程可視性, 精確時點績效, 過程一致性和無缺 陷。
(2) $6 \sigma$ 物流 (6 Sigma Logistics) : $6 \sigma$ 物流是 $6 \sigma$ 在物 流管理中的應用。6 $\sigma$ 是過程設計和提高的方法, 它的目標是在滿足客戶主要的品質要求方面達到 近乎完美的境地。它注重應用、結果和成功實施的 要素等方面。

(3) 閉環物流與逆向物流 (Closed Loop Logistics and Reverse Logistics): 閉環物流的概念, 是正向物 流和供應鉠、逆向物流和儲存能力的集成。它主要 應用 在售後服務、零部件更換（高科技產業）、 未出售、未使用、廢棄物的回收、回召或有缺陷的 產品等。

（4）精實供應鏈 (Lean Supply Chain)：精實供應鏈的 概念是精實原理與供應鏈結合, 是對精實物流的進 一步發展。精實管理為減少浪費、降低成本、縮短 操作週期、增加客戶價值從而增強企業的競爭優勢。 精實供應鏈的基本計劃方法是設定企業目標、部門 目標、操作目標, 明確現有績效與目標值的差別認 定, 制定達到預期目標的時間和要求。

\section{4. 物流與供應鏈與管理發展趨勢}

物流的概念起源於 20 世紀初, 然而隨著製造技術和管 理技術不斷提升, 終於達到盡頭, 企業發現已無法僅藉由 提高生產技術來降低總體成本，因此將研究的焦點自生產 領域轉向物流管理, 轉而思考如何在產品配送的過程中有 效降低成本與提高服務品質, 促使企業在競爭激烈的環境 中再度創造利潤。物流產業在科技進步和管理技術創新下, 經歷了從量到質的變化過程, 全球物流已經進入供應鏈時 代。以目前美國物流產業發展之主題, 給出了物流趨勢的 目標，而精實物流、閉環物流、6 0 供應鏈、精實供應鍕、 RFID等新概念、新技術, 則對物流產業的發展產生了直接 與間接的影響, 成為不可忽視的問題。快速變化的世界對 供應鏈管理、物流、金流、資訊流等均帶來了嚴苛的挑戰, 物流產業必須自身變革, 才能應對挑戰。因此, 物流從量 到質的變化進入供應鏈時代。

美國物流協會於2005年1月1日，正式更名為「美國供 應鏈管理專業協會」（CSCMP）。這意義揭示了 21 世紀國 際物流發展的主流趨勢為供應鏈整合管理。物流專業人員 的角色已經發生改變, 不僅包括物流的內容, 而且涉及採 購、生產運作、市場、行銷等功能, 並不斷於組織內部與 組織外部的人員進行溝通、互動。物流產業之運輸和倉儲 更為廣泛、深遠, 更注重管理技術對傳統產業的改造和升 級。依美國物流協會發佈了最新的供應鏈管理概念, 其中 包含對涉及採購、外包、轉化等過程的全部計劃和管理活 動和全部物流管理活動。更重要的是, 它也包括了與夥伴 之間的協調與合作, 涉及供應商、中間商、第三方服務供 應商和客戶。供應鏈管理是企業內部和企業之間的供給和 需求管理的整合。

\section{1. 台灣國際物流供應鏈發展現況}

供應鏈管理是一個用來整合採購、設計、生產、配送 和顧客服務從上游至下游供應鏈的整體流程, 其中包含資 
源供應商、供應商、企業內部營運、零售商和最終顧客, 更涵蓋了物流、資訊流及資金流，將需求與市場預測、訂 單、庫存、補貨、生產排程、生產規劃、運輸配送等資料 加以串連與流通, 使得整體供應鏈的供需能見度提高, 降 低長鞭效應, 使廠商能夠真正根據顧客與市場的需求變化 快速地提出回應以有效提升企業的競爭力。

供應鏈整合己成全球趨勢, 在全球分工的時代, 企業 經營競爭也轉為上下游產業供應鏈整合的競爭, 目前亞洲 在全球經濟扮演的角色, 已由世界工廠轉變為世界消費中 心躍居全球經濟最大成長動能, 整個亞洲經濟成長趨勢也 正牽動全球經貿版圖消長, 因此供應鏈管理不僅已成為企 業勝出關鍵, 能善用供應鏈管理模式, 即能取得企業成長 利基，進而掌握亞洲市場脈動。

在世界銀行最新公布的的統計資料全球物流績效指 標(LPI), 台灣「物流績效指標(LPI)總排名」為全球第19 位, 顯示台灣的物流產業已逐步位居全球供應鏈之重要角 色, 未來台灣應積極參與區域經濟合作、擴大國際與兩岸 市場、透過自由化開放, 掌握「一帶一路」挑戰與商機, 同時透過跨域整合、擴大市場利基、科技應用, 結合創新 的商業模式提升物流產業的附加價值, 才能為產業與顧客 創造最大效益。

\section{2. 台灣國際物流供應鏈發展策略}

台灣物流產業的發展對照政府所推動的計畫分為兩 個階段, 第一階段為「全球商業鍕整合及物流運籌 $\mathrm{e}$ 計畫」, 第二階段為「國際物流供應鏈管理服務發展計畫」，而供 應鏈管理服務業將會是未來數年的發展重點。第一階段的 推動重心, 是為國際物流業者轉型為供應鏈管理服務業奠 定基礎。大型國際物流業者重點放在擴展海外的據點, 物 流業要擴展業務至國外, 主要方式有三種: 分別為設立分 公司; 透過國外代理商; 策略聯盟。國內主要是採取跨國 策略聯盟, 其投資金額較少, 且能擁有部分經營主導權, 另外還有風險分擔和資源互補等優點。由於台灣的物流業 者多數為中小企業, 因此台灣經濟部也同時推動共同物流 平台整合計畫。第二階段的發展, 目的在於強化臺灣國際 物流的服務能力, 推動的重點包含「加值併貨與物流配銷 服務」及「售後維修服務」。

\section{5. 台灣物流供應鏈業面臨的挑戰}

目前台灣商業環境受到全球化、國際競爭的影響使得 產品生命週期減短、客戶要求愈來愈高、利潤萎縮、可用 資源減少的影響, 企業莫不訂定新的商業目標尋求解決方 案。

\section{1. 台灣物流供應鏈物應鏈業當前所面臨的問題}

2016年台灣物流供應鏈企業當前所面臨的問題, 在內 需市場方面有: 原物料持續上漲、薪資水準、勞保制度、 健保制度、企業所在地環境與其他相關公共事務、政府赤 字等問題; 在外貿市場方面有: 大陸經濟成長、兩岸經貿 開放腳步放緩、歐美企業陸續從亞洲將生產基地移回歐美 區域及人工廉價的印尼、越南等國家; 由於地球溫室效應
的影響, 近年來天然災害害不斷, 也造成全球供應鏈失衡、 阻斷的危機。台灣國際物流業者要轉型為供應鏈管理服務 業, 主要的挑戰包括服務能力的整合以及與異業的合作, 以跨國異業整合來說, 就可以掌握核心業務互補、流程整 合和資訊系統整合等三大原則。

\section{2. 台灣物流供應鏈管理未來的 5 大挑戰}

全球化與原物料價格上漲、價值活動的轉移、商品型 態的改變、供應鏈的永續維運、相關法規的遵循將會是供 應鏈管理未來的 5 大挑戰。

挑戰1. 全球化與原物料價格上漲: 全球布局、油價與 原物料上漲、各國當地的制度如中國勞動合同法都將影響 供應鏈的規畫。

挑戰2. 價值活動的轉移: 協同設計將帶動供應鏈與設 計鏈的整合，自有品牌發展則會促使企業開始規畫顧客鏈。

挑戰3. 商品型態的改變: 流通業者增加自有品牌產品 必須提升與供應商協同設計的能力, 進口產品增加則要提 升預測與補貨能力。

挑戰4. 供應鏈的永續維運: 為了讓供應鏈管理能跟上 經營模式的轉變, 關鍵績效指標監控將更重要。

挑戰5. 相關法規的遵循：歐盟的EuP指令和世界關務 組織推動的供應鏈安全計畫AEO將成為企業走向國際市場 的挑戰。

\section{6. 建構最佳鏈系統}

\section{1. 物流佈建與整合}

台灣企業在海外佈局已久，除了製造業將生產製造廠 移至海外，隨著服務業快速發展流通服務業也有佈局，除 了品牌商佈局自有通路, 不少專業通路商也跨足行銷海外, 在物流方面, 一些產業為加強供應鏈效能, 開始於海外各 地佈建物流儲運據點。因此, 有效整合、共享資源實屬重 要, 掌握與應用現有已佈局之物流資源, 包括土地、倉儲 據點、運輸能量、專業經理人等, 先望固既有物流資源再 予以擴大補強, 不但可加速國內業者伸展觸角進行國際佈 局，亦可避免已投資的資源因利用率不足導致成效不彰。 政府應調研目標與整合方向, 以有效整合、共享海外物流 資源為目的, 掌握與應用現有企業已佈局之物流資源為策 略手段, 調查企業海外佈局之物流據點與運作狀沉, 逐步 建立海外物流資源資料庫; 由了解各公司狀況開始, 發覺 缺口予以補強、掌握優勢資源進行分享、同時分析網絡進 行整合企業網絡連結、資源互補與供應鏈整合機會。

\section{2. 服務加值與創新}

從既有物流供應鏈業務延伸加值服務在奠定了強化 服務內容與深度與異業合作的整合基礎後, 國際物流業者 可以根據不同產業的需求，延伸不同的服務。根據美國供 應鏈協會 (Supply Chain Counci1) 提出供應鏈作業的參 考模式, 將供應鏈管理作業流程分為規畫(Plan)、採購 (Source)、製造(Make)、配銷物流(Deliver)與貨品退回 (Return), 國際物流業者便可根據不同的產業需求, 以此 
發展出各種加值服務。以採購來說, 有些企業為了減少對 不同物流業者、供應商的管理，會與某一兩家物流業者合 作, 由該物流業者做為單一聯絡窗口, 提供與其他物流業 和供應商的聯絡, 負責如訂單、補貨等服務。由於台灣有 地理優勢之故, 以配銷物流的流程而言, 除了發展國際物 流、運輸管理與倉儲管理外，還可朝向多國加值併貨服務 與區域配銷中心發展。以多國加值併貨服務來說, 主要是 做為將亞太區生產的產品運輸到歐美地區的中介站, 該中 介站可提供品質控管、包裝、測試等服務, 區域配銷中心 則是做為歐美地區產品進入亞太區的中介站, 提供如分裝、 測試或組裝等服務。在貨品退回部分, 除了增加過期產品、 環保回收等逆物流的需求外, 維修中心也是可以發展的方 向, 國際物流業者可以作為企業的倉儲、補貨、售後服務 中心，目前許多國際物流業者便是這樣發展。製造業的服 務內容除了庫存管理與供應商管理庫存外, 則要更強調檢 測品管服務。資訊電子崖業對於維修中心的需求會較高, 零售業者的供應商數量通常很多, 對供應商管理庫存委外 的需求就可能較高。因此國際物流業者要轉型前, 要先了 解該產業的未來發展以及客戶的需求, 以定義好新的商業 模式。

\section{3. 資訊系統整合}

資訊網路及電子商務引導物流供應鏈型態變革於臺 灣的中小企業居多，資金的支援也是一大阻礙。政府應該 鼓勵物流業者自己有能力募得資金, 以因應持續成長需求。 在轉型為供應鏈管理服務業的過程中, 對於供應鏈管理而 言, 即時貨況追踀與供應鍕流程透明化是很大的要素, 而 資訊科技是讓資訊透明化的基礎, 因此資訊科技e化能力 可使企業強化服務內容。根據2014年國際企業物流與供應 鏈管理經理人的調查 (2014 Third-Party Logistics: Results and Finding of the 11th Annual Study)結果, 92\%受訪企業都表示IT服務能力是物流業必備的專業服務 能力, 也是企業評選3PL的重要評比要件, 由此可以看出, 在國際物流業者轉型為供應鏈服務業的趨勢下, 資訊化對 企業會越來越重要。隨著資訊網路科技的進步, 物流業朝 向電子商務發展將成為市場主流, 電子商務運作模式下各 式商品之銷售及服務, 均需藉由物流或運輸配送服務, 通 路改變的趨勢將朝向消費者主導、服務需求引導之發展方 向。

\section{7. 結論與建議}

\section{1. 結論}

運籌物流目前已是商業的成功基礎, 建立完善的物流 後勤支援, 物流供應鏈管理是物流業者在面對全球化時代 之際, 打造競爭力的重要關鍵。由於網際網路的出現, 讓 物流業者面對的變化速度也越來越快, 全球化時代的來臨, 更讓供應鍕的競爭格局變得更加複雜, 物流業者已經不能 靠標準產品行銷全球，而是要根據不同地區的需求，提供 不同的產品到全球各地, 這也就是全球運籌管理的重要性 所在。除了全球化的影響外, 台灣產業價值活動的轉移趨 勢, 也將帶動供應鍕的轉變。台灣的製造業轉型為製造服
務業的趨勢也越來越明顯, 除了技術也提升其他服務能力, 包括物流、服務、技術、資訊等。在這樣的發展下, 業者 要關注的就不只是製造的問題而已, 而且企業與客戶、供 應商的關係也會有所變化。其中, 協同設計將會是重要發 展, 因而企業規畫供應鏈時要再強化與設計鈛的整合。就 必須更重視服務、通路、銷售等需求，因此也會帶動企業 再發展出顧客鏈。

物流業因具有創造產品、資訊、服務等附加價值之功 效, 在企業產銷組合中已成為最重要的經濟活動之一，對 於提升台灣產業在全球市場之競爭力, 經濟持續成長, 以 及達成亞太營運中心之目標, 現代化物流業實扮演積極而 不可或缺之重要角色。因此, 政府部門應儘快加速基礎設 施之建設與法規制度之改革, 以提供公平合理之物流業營 運環境, 而產業部門亦應對現代化物流策略有所認識, 並 積極促進物流業之發展, 佐以現代化資訊及通訊科技支援 物流供應鏈管理, 協助物流業者提升效率、降低成本及創 造策略性之持久競爭優勢, 為台灣地區未來之經濟發展再 創奇蹟。

\section{2. 建議}

（1）發展國際物流之核心實力, 進行關、港、貿等跨部 會整合, 以強化在台企業之全球運籌能力。

（2）充分運用兩岸經濟互動與直航契機，建立物流運籌 政策配套, 積極推動臺灣與亞太地區產業供應之串 接合作。

（3）因應台灣與中國大陸簽署「海峽兩岸經濟合作架構 協議」（ECFA）, 積極布建全球運籌服務網絡, 開展 臺灣經貿發展的黃金10年; 於2020年，打造臺灣成 為亞太區域物流加值及供應鏈資源整合之重要據 點。

全球運籌布局的難度相當高, 不僅要顧慮各個據點的 資源配置和管理, 走向全球運籌後, 物流業者需對企業流 程再造和重新設計供應鏈的問題。台灣以中小企業居多, 而金融業多隸屬在財政部下，物流業中如海運、空運、報 關等不同業者隸屬在不同的政府單位下, 若要整合勢必要 面臨跨部會的合作，其難度很高，因此資金的支援將會是 一大阻礙。政府可以鼓勵物流業者上市、上櫃, 讓企業自 己有能力募得資金, 以因應持續成長之需求, 此外, 也可 協助該產業發展出國際物流控股公司。

由於台有地理優勢之故，以配銷物流的流程而言，除 了發展國際物流、運輸管理與倉儲管理外, 還朝向多國加 值併貨服務, 與區域配銷中心發展。以多國加值併貨服務 來說, 主要是做為將亞太區生產的產品運輸到歐美地區的 中介站, 該中介站可提供品質控管、包裝、測試等服務, 區域配銷中心則是做為歐美地區產品進入亞太區的中介 站, 提供如分裝、測試或組裝等服務。在貨品退回部分, 除了增加過期產品、環保回收等逆物流的需求外, 維修中 心也是可以發展的方向, 國際物流業者可以作為企業的倉 儲、補貨、售後服務中心, 目前許多國際物流業者便是這 樣發展。製造業的服務內容除了庫存管理與供應商管理庫 存外, 未來則要更強調檢測品管服務。至於企業該延伸哪 些服務, 則會受不同產業影響, 資訊電子產業對於維修中 
心的需求會較高, 零售業者的供應商數量通常很多, 對製 造業委外的需求就可能較高。因此國際物流業者要轉型前, 要先了解該產業的未來發展以及客戶的需求, 與供應鏈模 式及管理。

\section{参考文献}

［1］台灣行政院國家發展委員會 http: //www. ndc. gov. tw/cp. aspx?n=7F220D7E656BE749\&s $=5 \mathrm{C} 3 \mathrm{~F} 3 \mathrm{ED} 6 \mathrm{E} 0$.

[2] 台灣經濟研究院

http://tie. tier. org. tw/db/article/list. asp?code=IN D30-12\&ind_type=midind.

［3］台灣經濟部商業司，2015台灣物流年鑑，臺北市。

[4] 世界經濟論壇: http://www. weforum. org/en/index. htm.

[5] Hsin Hsin Chang, Yao-Chuan Tsai, and Che-Hao Hsu. "E-procurement and supply chain performance." Supply Chain Management. 18 (2013).

[6] Michael Tracey and Roger Neuhaus. "Purchasing' s role in global new product-process development projects." Journal of Purchasing and Supply Management. (2013).

[7] Mehmet Melikoglu. "Vision 2023: Forecasting Turkey's natural gas demand between 2013 and 2030. ” Renewable and Sustainable Energy Reviews. (2013).

[8] Daniel Chick, Glyn Watson, Helen Walker, Zoe Radnor and Robert Johnston. "Theoretical perspectives in purchasing and supply chain management: an analysis of the literature." Supply Chain Management. 17 (2012).

[9] Y. - C. Yang. “A Comparative Analysis of Free Trade Zone Policies in Taiwan and Korea based on a Port Hinterland Perspective." The Asian Journal of Shipping and Logistics. 25 (2009): 273-303.

[10] Z. Wan, Y. Zhang, X. F. Wang, and J. H. Chen. "Policy and politics behind Shanghai's Free Trade Zone
Program. ” Journal of Transport Geography. 34 (2014) : $1-6$.

[11] Y. -C. Yang and S. -L. Chen. "Determinants of global logistics hub ports: Comparison of the port development policies of Taiwan, Korea, and Japan.” Transport Policy. 45 (2016) : 179-189.

\section{作者简介}

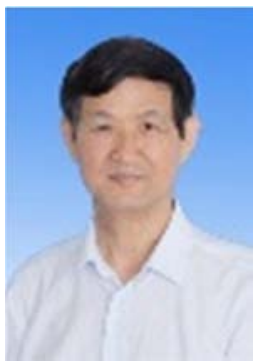

趙定濤, 教授，男，現任中國科學技術 大學商學院教授, 博導。專業方向：戰 略管理與政策分析，學術成果：期刊發 表論文70餘篇, 書著6種。曾獲安徽省社 科優秀成果二等獎，科技進步三等獎， 自然科學優秀論文二等獎。

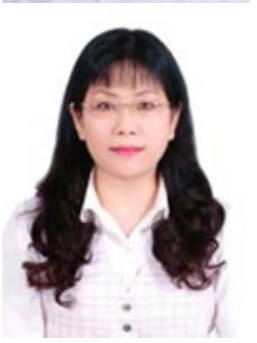

郭淑惠, 女, 中國科學技術大學管理科 學與工程博士生。高群裝卸股份有限公 司財務長。

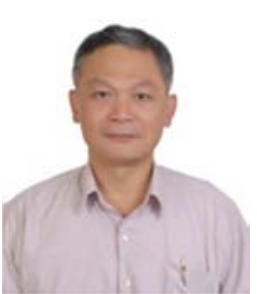

王天津，男，博士 (UWS，UK)，高雄應用 科技大學教授，管理學院院長，中國科 學技術大學客座教授(合肥)。創新四種 方法：Fuzzy Linguistic Preference Relations (Fuzzy LinPreRa)、Fuzzy VIKOR 、 Fuzzy PROMETHEE 、 Fuzzy Incomplete Linguistic Preference Relations (Fuzzy InLinPreRa)。期刊審稿：Information Sciences、European Journal of Operational Research、 IEEE Transactions on Fuzzy Systems 、Applied Soft Computing、Applied Mathematical Modelling。 